\title{
Environmental and climate risks in financial analysis
}

\author{
M. Onischka \\ Wuppertal Institute for Environment, Energy and Climate, Germany
}

\begin{abstract}
The assessment and consideration of risks in the analysis of companies and projects play an important role in investment decisions. In the context of climate change new significant types of risk arise, such as physical risk, regulatory risk or risk of reputation. It can be shown that climate risks are additive, increasing the whole risk exposure significantly. Relevant studies have shown that depending on the sector climate risks will affect the value of assets (value at risk) up to double-digit percentage. Applying common methods and procedures these risks are generally determined and measured insufficiently. Thus, the provision for environmental and climate risks in the granting of credits, sell-side/buy-side research or due diligences is not adequate, although existing approaches would generally allow a valuation of these risks.

The main target of this paper is firstly to analyse the problem of the 'debasement' of historical data especially in the light of climate change. In addition to that, relevant approaches for the process of financial analysis will be outlined in order to implement environmental and climate risks by means of adjusted risk premiums. In this context these approaches represent practical potentialities for the implementation of risk premiums as well as fundamental factors that have an impact on the investment decision. Here an important connection between risk measure, economic reference parameter and valuation method is developed.
\end{abstract}

Keywords: climate change, risk assessment, valuation, risk management, risk measure, financial analysis, environmental risk. 


\section{Background}

In practise the valuation of companies - be it the assessment of the 'fair' company value or just its creditworthiness - is usually realized by discounting future profits/free cash flows, sometimes even by means of a comparison of similar companies of a peer group. In any case, only those aspects are considered that influence the value drivers of the business success directly; that are monetary variables (Hitchner [5]). The human influence to the ecological system usually occurs as external effects only. At first they do not have any influence to the monetary or business sphere and therefore are not considered in valuation processes. Concerning normal valuations there is no interest in the objective or true value of a company or project that regards externalities too. On the contrary the market value is relevant only because the valuation is usually made for a specific purpose (e.g. acquisition, stock analysis).

From a macroeconomical point of view such an microeconomical optimization is not welfare-optimal because not considered damages and cost will lead to a more intense use and pollution of the environment (Pigou [13]). By contrast, climate change influences the financial performance of companies/projects directly because in part external effects will be internalized. Climate change has the specific feature that due to the greenhouse gas emissions such a strong feedback by the ecosystem occurs that impacts to the economics system reach relevant financial dimensions. The fact that both politics and society are already reacting - e.g. via political procedures - influences the value drivers of companies directly. Therefore climate change becomes relevant for the valuation of companies and projects, too. In the last years several studies have been published which carefully estimate costs and decline in company values as a result of climate change. The estimations refer to different economic levels (worldwide, national wide, industry-specific) and include a number of simplifying assumptions (for more details and an overview of selected estimations of economical impacts refer to DIW [1], Onischka [14], Stern [19] and WestLB [20]).

Climate change does not only affect companies by extreme weather events like storms, droughts or floods. For European companies future damages and losses caused by weather will turn out to be less significant compared to companies in regions with relative high climate exposure (IPCC [9]). The business development is affected by climate change through three channels: operating business, investments and capital costs. The operating business is especially influenced by changing consumer demand for less greenhouse gas intensive technologies or products. As a result, both cost structure and sales volume are changing: Turnover, cash flows, profit etc. are inevitably affected. The second channel are investments, with long-term investments in fixed assets, production technologies and R\&D as the most relevant. Last not least also costs of financing add up from cost of debt and cost of equity (Stern [19]). As soon as banks start implementing aspects of carbon intensity into their corporate credit rating the cost of debt will change (Onischka and Orbach [11]). An increasing part of the investors are also trying to consider the impact of climate change to 
the business development of their assets. A growing demand for risk-adjusted premiums on the return of equity will be the result.(for instance see: The Carbon Disclosure Project. www.cdproject.net)

If - as a result of climate change - relevant parameters and value drivers change and are predictable under uncertainty only, business-specific risks will emerge (Onischka [14]). In the previous years a distinction into four risk categories has been established (physical risk, regulatory risk, reputational risks, litigational risk)(For a more detailed overview of climate risks, refer to [19]) and influence the value drivers and therefore a company's performance directly. The impression could arise that these risks are already covered by conventional business risks, which are typically estimated in company valuations or ratings. However, climate change has the specific feature that it virtually influences industries and companies as an external effect and therefore does increase/diminish the risk exposure additional to the conventional business risks. The estimates of various up to now works show quite clearly that climate change is economically no zero-sum game, in truth it will bring net losses whereas industries will be affected differently (Stern [19]). The occurrance of effects of diversification may be limited only. In the result economic risks due to climate change are to be understood as additional risk which are covered with the conventional financial analysis/rating only insufficiently.

In this paper the thesis is supported that climate risks are considered insufficiently in conventional methods and approaches. In this context the important issue arises in which shape data and information need to be provided to ensure their usability. Above all, potential differences between on the one hand feasible statistical risk measures and on the other hand relevant risk measures might be interesting, as well as practice-relevant combinations of reference parameters and valuations methods. Other important issues like the practical methods for ascertaining the required data and risk measures (e.g. by means of data simulation or subjective probabilities) is not covered by this paper. The structure of the paper is as follows: Firstly, in chapter two the attention will directed to the analysis why historical data seem to be not feasible for the consideration of climate change as well as other environmental factors and therefore new approaches are required in future. In chapter three a simple systematic will be worked out that shows how climate risks shall be measured resp. quantified to ensure their ability for valuation in practice relevant methods. At this a distinction between risk measure, reference parameter and practical approach will made, leading to an assessment that will carry out useful and feasible combination of factors of each category.

\section{Debasement of historical data}

In the centre of company/project assessments stands the analysis of the current situation of a company's assets, liquidity and profitability. Based on this status quo as well as historical data of the company, trends are derived and projections are calculated. Typically, selected key business ratios are estimated to facilitate forecasts for future periods. For simplification reasons trends or the status quo 
are often extrapolated. So in general historical data are the starting point for any assessment or valuation. Concerning the concrete methodology different approaches are used. Sometimes only the asset value, sometimes only the capitalised earnings value, sometimes comparisons based on key business ratios, and sometimes hybrid forms are used. The methodical alternative at project/company valuations is the summation of future costs as well as profits. Experience and cost data of the past are usually the fundament of any calculation, too.

Regarding climate risk there are several specifical requirements on data quality. Existing historical data of weather or weather extremes (e.g. quantity and power of storms) are ineligibly for forecast (Schwartz and Randall [17]). Appropriate climate models show that there was, there is and there will be nonlinear, time-delayed and even erratic changes at direct and indirect climate effects (Fischer et al. [2]). Therefore it is problematic to draw conclusion from the historical climate exposure (that is the monetary priced impacts of risk as a result of climate phenomenon) because this will result in significant false estimations. This is even true although a multitude of sectors (e.g. agriculture, fishing, logistics/ transporting, tourism) have already been exposed to physical climate and weather risk like heat/cold waves, high/low water, storms or El Niño. But for the available economic data (ca. 200 years) there were no fundamental changes of climate in such a scale, which would have had significant impacts on cash flows of companies. So it can be stated that without any adjustments the empirical climate exposure has no direct significance, the historical data are so to speak 'debased'.

However, physical data are not the only information that has influence on the business success. Especially future regulations and changing reputation play a central role. Empirically, regulations can be estimated by logit- and probitmodels.(for an introduction to such models refer to Ronning [15]) But these models presume that the structural connection between impact factors and regulations will last for the future. But for climate-related regulations various problems remain. For example there are - if at all - only a few relevant and comparable regulations. Observable events only occur within large intervals (e.g. in terms of legislation) and their frequencies make strong statistical conclusions almost impossible. As soon as such events occur they will have significant impact on business developments. As a rule, a certain regulation (e.g. limits for $\mathrm{CO} 2$-emission of car per kilometre) is related to a certain object and appears in this form only once. Trends or causalities based on a historical development are not possible because of missing comparability. So it can be emphasized again that historical data - be it data of weather related events of regulations - are unsuitable for the assessment of future development. However, this result contradicts the already discussed and established practise to extrapolate the historical development to the futures with small adjustments only. The question remains what are adequately solutions to avoid wrong conclusions as a result of wrong underlying database. Here are three possible suggestions:

Possibility 1: Lump-sum risk premiums are chosen in an extent that they cover possible divergences of the conventional estimated variables in an 
acceptable confidence interval. Though, this would have the disadvantage that due to the ignorance about future events, risk premiums turn out to be considerably bigger than actually required. The result would be a systematic undervaluation.

Possibility 2: For several time frames estimations about the net cost of climate change already exist for national and industry level (ref. to chapter 2.1). In the context of a Monte-Carlo-simulation qualities of historical data series are connected with such kind of additional parameters to new synthetic, simulated data series.

Possibility 3: Subjective apriori probabilities will be referred to several formed scenarios and finally used for the calculation of a company's value. Although these probabilities can be derived from just from the analyst's a priori probabilities; however, the Bayesian Risk Management usually uses an aggregation of expert based knowledge. By this approach existing information about climate change or its consequence that is not included in formal data can there be made usable up to risk measures.

Due to the multidimensional influence of climate change there is none state of art approach that enables to deal with this data-relating problems in practice. The approaches, which are on hand or still to be developed (e.g. Bayesian Risk Management) are not yet tested in practice in a scale that allows characterizing a satisfactory solution of the problem (Haas and Jaeger [4]).

\section{Relevant approaches in financial analysis and risk controlling}

\subsection{Interrelationship between important elements in risk management}

At the valuation of companies or projects risk itself plays a subordinate role only. Rather the focus is on a preferably realistic, monetary valuation of the object (Spreman [18]). In this meaning risk has merely to be understood as a probability for a possible variation of the estimate from the 'real' value on a certain scale. This overall risk arises primarily in consequence of the basic assumptions of the assessment. On the one hand, these are the model assumptions. However, on the other hand the estimates and forecasts about the future financial development do have a stronger effect. If the risk shall be considered in the valuation in a way that also the target value (project or company value) could be adjusted, the risks must be treated systematically within the whole valuation process. These (risk) valuations are not only used for financial analysis; risk analysis and assessments of all sorts of valuation objects take place at financial service providers in the context of risk controlling particularly. In this context risk controlling has to be understood as part of a general, often interdivisional risk management, which identifies risks and measures financial consequences. In addition it is also used for the control of the risk policy (Johanning et al. [8]).

In practice, information about climate-related risks appear in two forms: First as an uncertainty about value drivers of the financial figures of companies; 
second, as more general external information, for instance scientific or expertbased estimations about the net cost of climate change for economies or selected industries. To ensure a systematic consideration of both forms of information they should have some influence on so-called risk measures. At this, risk measures are the mathematical description of the characteristics of these risk information. Usually these kinds of information are extracted out of statistics or stochastic, sometimes only rough risk information is accessible. For example in the recent reports of the Intergovernmental Panel on Climate Change (IPCC) probabilities to certain statements and results are only made verbal.(certain verbal expressions like "very likely" will be referred to certain range of probability. In the case of "very likely" this verbal expression is often referred to a probability between $90 \%$ and $99 \%$.)

The valuation process before the use of any valuation method is similar for both financial analysis and risk controlling, especially regarding its content and procedure. Therefore the following analysis covers both areas. Figure 1 illustrates a simplified connection between the elements of the valuation process. Both in practice and in literature a clear separation between these elements is not made. After their collection, the 'financial data' are condensed and as a rule important variables (for example in form of value drivers) are identified that might have a big influence to the company's value resp. to the valuation item. This step is called later 'data analysis'. Either risk information refers to these data directly or/and external risk information will be added. External risk information in this context means that general information about risk and probabilities - e.g. information from IPCC or estimations of relevant studies about certain industries - will be taken into account. As a general rule all information will be condensed to a single 'risk measure'. Since the aim of the valuation process is a risk adjusted valuated variable, the risk measure is used along with an economical 'reference parameter'. Here, the risk measure indicates the ,amount' of risk meanwhile the reference parameter can be seen as a , unit' of an economical parameter. It is quite obvious that the characteristics of the risk measure depend on the kind of reference parameter. One example: Imagine a company with a high carbon and climate risk exposure. The risk information will highly differ if they are referred to the company's profitability, company value or its market share. To some extent the methods of valuation discern significantly, for technical reasons the use of just one general reference parameter is therefore not feasible.(this might be one of the main reasons why there does not exist only one single standard method for the consideration of climate and environmental risk.) If this context is taken into account, each in practice relevant method will entail one (or few) economical reference parameter; this reference parameter will entail a certain group of risk measures. In contrast to conventional subjects of risk assessment the effort to achieve these risk information can be significant higher and more time-consuming. Therefore, regarding climate change it is crucial to know about which variable risk information is needed and which kind of measure fore this information must be provided. The discussed simplified interrelationships between these elements are visualized in figure 1 . In the following chapter the mentioned elements of the valuation process - i.e. risk 
measure, reference parameter and valuation method - will be discussed separately and then consolidated with regard to practicable combinations.

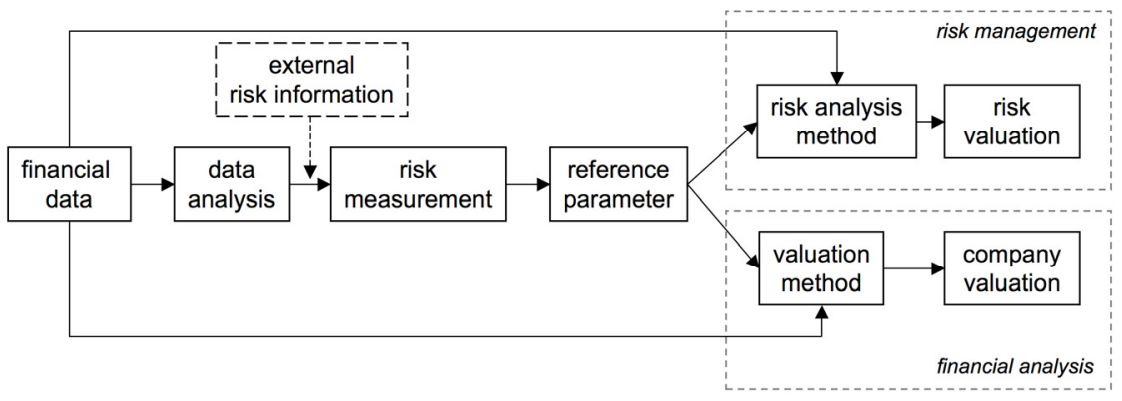

Figure 1: Interrelationship of important elements within the valuation process.

\subsection{Systemization of risk measurements, economic reference parameters and methods for valuations}

Risk measures describe identified risks quantitatively by suitable probability distributions. In practice, usually a separate estimation of the expected amount of a payment and the risk of its settlement is carried out. Risk measures can refer to single risks (e.g. damage of fixed assets) but also to the complete risk of a company (e.g. profit). Risks are often described by either the amount of damage and the probability of its occurrence or by a standard deviation. These and other important risk measures can be systemized within the three following groups. (In general different systematizations are possible as well (e.g. security related vs. failure related) but in the context of this analysis not appropriate. For further systemization of risk measures refer to Reichling et al [14] and Gleisner [3].)

\begin{tabular}{|l|l|l|}
\hline Two-sided risk measures & One-sided risk measures & Other risk measures \\
\hline Standard deviation & Value at risk (Var) & Volatility (financial)* \\
\hline Variance & Conditional value at risk (Cvar) & \\
\hline $\begin{array}{l}\text { Covariance/correlation- } \\
\text { coefficient }\end{array}$ & Equity requirement (ER) & \\
\hline $\begin{array}{l}\text { Density function (not normal } \\
\text { distributed) }\end{array}$ & Lower Partial Moments (LPM) & \\
\hline
\end{tabular}

Figure 2: $\quad$ Systemization of risk measures. *In opposite to the mathematical definition (standard deviation of a random variable) this volatility refers to the definition used in the financial world. In these terms volatility is to be understood as standard deviation of historical changes of an observable parameter.

The choice of an economical reference parameter depends strongly on the aims and intentions of the ,risk analyst'. While the investor is primarily interested in potential changes on the return of investments, a fundamental 
oriented analyst is rather concerned about variances of value drivers of the free cash flow of a company (e.g. certain cost structures). Economics reference parameters for risk information can be differentiated into several groups. On the one hand there are relative parameters, like types of 'return of investments' as well as 'discount factors'. On the other hand 'value drivers' and absolute to the type of 'absolute monetary variables' can be subsumed to absolute parameters. If the assumptions of the standard models in finance would be valid, these groups should provide similar outcomes as a result of their formal relationship. However, in reality the financial markets are neither full efficient nor complete, so that segmentation into these four groups is useful.

Which concrete method is used for valuation strongly depends on the object to be valuated. As a rule in financial analysis this is the value of a company - be it the market value or the fundamental value. In risk controlling however, merely the monetary risk is isolated. So in practice, totally different methods are used. In the Appendix methods for the valuation of companies/projects are listed according to their relevance for practice, as well as approaches used in risk management.

\subsection{Synopsis}

As already mentioned, the most valuation methods can be assigned to only one (in some case to two) economic reference parameter with whose value risk can be expanded into the valuation. For the methods with a high relevance for practice these matches are listed in the following table. Technically this table is a synopsis of chapter 3.2 and figures 3 and 4 of the Appendix, whereas only methods with high practice relevance are considered. Individual explanations for these matches can be set aside because they are the logical result of the

\begin{tabular}{|l|l|l|}
\hline $\begin{array}{l}\text { Practice relevant method } \\
\text { for the management of risk }\end{array}$ & $\begin{array}{l}\text { Economical reference } \\
\text { parameter }\end{array}$ & $\begin{array}{l}\text { From a logical point of view } \\
\text { usable risk measure }\end{array}$ \\
\hline $\begin{array}{l}\text { Discounted Cash Flow } \\
\text { Equity/Entity * }\end{array}$ & Discount rate/discount factor & One-sided risk measure \\
\hline Gross rental method & Absolute monetary variables & $\begin{array}{l}\text { One-sided and tow-sided risk } \\
\text { measures }\end{array}$ \\
\hline Combined approaches ** & Absolute monetary variables & $\begin{array}{l}\text { One-sided and tow-sided risk } \\
\text { measures }\end{array}$ \\
\hline Multiplier method & Absolute monetary variables & $\begin{array}{l}\text { One-sided and tow-sided risk } \\
\text { measures }\end{array}$ \\
\hline Capital Asset Pricing Model & Return of investment & Two-sided risk measures \\
\hline Sharp Ratio & Return of investment & Other risk measures \\
\hline $\begin{array}{l}\text { Sensitivity analysis } \\
\text { Risk simulation with VAR } \\
\text { variables }\end{array}$ & $\begin{array}{l}\text { Independent from only one economical reference } \\
\text { parameter/risk measure } \\
* * \text { value drivers may be an alternative reference parameter. }\end{array}$ & Monetary variables \\
\hline
\end{tabular}

Figure 3: Combination of valuation method, reference parameter and risk measure. 


\begin{tabular}{|c|c|c|}
\hline Method & Main idea & $\begin{array}{l}\text { Relevance } \\
\text { for practice }\end{array}$ \\
\hline \multicolumn{3}{|c|}{ Discounting methods } \\
\hline Discounted Cash Flow - Equity & \multirow{6}{*}{$\begin{array}{l}\text { The net present value of the estimated } \\
\text { future cash flows (usually free cash flows) } \\
\text { or profits (dividends or annual net profits) } \\
\text { will be calculated. }\end{array}$} & High \\
\hline Discounted Cash Flow - Entity & & High \\
\hline Adjusted Present Value & & Medium \\
\hline Dividend Discount & & Low \\
\hline Gross rental method & & High \\
\hline Weighted Cost of Capital & & Low \\
\hline \multicolumn{3}{|c|}{ Net asset value methods } \\
\hline Net asset value approach & \multirow{3}{*}{$\begin{array}{l}\text { Assessment of the net value of the assets } \\
\text { of a company }\end{array}$} & Low \\
\hline Combined approach & & High \\
\hline Liquidations approach & & Low \\
\hline \multicolumn{3}{|c|}{ Multiplier methods } \\
\hline Multiplier method & $\begin{array}{l}\text { Deduction of the company value from real } \\
\text { purchase prices resp. market values of } \\
\text { similar companies }\end{array}$ & High \\
\hline \multicolumn{3}{|c|}{ Approaches of the portfolio theory } \\
\hline Capital Asset Pricing Model & \multirow{3}{*}{$\begin{array}{l}\text { Minimization of the unsystematic risk. } \\
\text { Valuations are made out of risk-return- } \\
\text { combinations of the market. }\end{array}$} & High \\
\hline Arbitrage Pricing Model & & Low \\
\hline Sharp Ratio & & High \\
\hline \multicolumn{3}{|c|}{ Real options } \\
\hline Real options & Valuation of possible strategic actions & Low \\
\hline
\end{tabular}

Figure 4: Systemization of valuation methods (for a more detailed description of these several methods refer for instance to [18] or Hockmann and Thießen [6]).

systematic of these methods. Only one simple example: The basic model of the CAPM makes a direct relationship of the return of a portfolio/security on the one hand, and its risk on the other hand. In this context the central economical reference parameter is the return on investment. Also determined by the methods resp. its assumptions, only one-sided risk measures can be used - in this case variances and covariances. Similar considerations are possible for the other methods. At the end only one feasible combination of valuation method, economic reference parameter and risk measure is reasonable:

\section{Conclusion}

There is at least one general result of this analysis: Depending on the used valuation method, risk shall only be valuated with economical reference parameters and risk measures that are feasible to the method resp. its assumptions. Though, this also implies that not every kind of mathematical information of risk (risk measure) can be used in practice. This aspect is of highly importance when climate or other environmental risks shall be considered because obtaining this kind of risk information will often take much more effort - for example the mentioned data adjustments in chapter 2 - than the assessment of conventional business risks. The information condensed in the systemization of this paper can be used to get an information what kind of requirements to risk information are needed to ensure an appropriate consideration of environmental 
risks in used valuation methods. At least the way of the discussed context of this synopsis might provide a good support how climate and environmental risks should be considered in risk assessments. As briefly discussed in chapter two, for valuations of companies/projects several risk categories are relevant but their value cannot be analysed with an historical database only. As soon as appropriate methodical solutions have been developed, regarding modified data can be used in the ways described by the systemization of this paper. Possible outcome might be several practical instruments that are used independently before starting the conventional valuation methods (like discounted cash flow, CAPM or VAR). Hereby climate and/or environmental aspects and risk can be taken into account adequately.

\section{Appendix}

Approaches for valuations of companies/projects: A variety of methods exist to determine the value of a company resp. project. It is possible to distinguish between five main groups of valuation models mentioned in figure 3. (The allocation of practice relevance is made out of rankings in literature/European practice guidebooks as well as the frequency of their appearance-even though it remains subjective.)

Approaches of risk management: Partly, the methods of the financial analysis are also applied at risk management, in particular elements of the portfolio theory. (For instance, based on the CAPM risk adjusted discount rates as well as the complete risk of a portfolio can be determined.) Quite often the result of specific methods in risk management is a discreet characterization of risk in the form of risk groups or rankings. This information will be used directly for activities in minimizing or hedging risks. Many methods of risk management used in practice are based on qualitative heuristics; therefore a reasonable use of quantitative risk information is not possible. For this reason quantitative methods are covered in figure 4 solely. (The allocation of practice relevance is made out of rankings in literature/practice guidebooks as well as the frequency of their appearance - even though it remains subjective.)

\begin{tabular}{|l|l|l|}
\hline Method & Field of application & $\begin{array}{l}\text { Relevance for } \\
\text { practice }\end{array}$ \\
\hline Sensitivity analysis & Financial risks & High \\
\hline Scenario techniques & $\begin{array}{l}\text { Market risks, external } \\
\text { developments }\end{array}$ & Medium \\
\hline Expectation-value-principle ( $\mu$-principle) & Quantifiable risks & Low \\
\hline $\begin{array}{l}\text { Risk simulation with VAR (e.g. ascertainment } \\
\text { of the minimum deposited equity according to } \\
\text { BASEL II) }\end{array}$ & Financial risk & High \\
\hline Lump-sum agios/disagios & Financial risks & Medium \\
\hline
\end{tabular}

Figure 5: Selected valuation methods of risk management (for a more detailed description of these methods refer for instance to Kuruc [9] or Reichling et al. [14]). 


\section{References}

[1] DIW, Klimawandel kostet die deutsche Volkswirtschaft Milliarden, DIW Wochenbericht, No. 11/2007.

[2] Fischer, H., et al. (eds). The Climate in Historical Times. Towards a Synthesis of Holocene Proxy Data and Climate Models. Berlin 2004.

[3] Gleisner, W., Risikomaße und Bewertung - Entscheidungen unter Unsicherheit und Erwartungsnutzentheorie, Risikomanager, 06/2006, pp.420.

[4] Haas, A., Jaeger, C., Agents, Bayes, and Climatic Risks - A Modular Modelling Approach, Advances in Geosciences, No. 4, pp. 3-7, 2005.

[5] Hitchner, J., Financial Valuation. Application and Models. New Jersey 2003.

[6] Hockmann, H., Thießen, F., Investmentbanking. 2nd Edition. Stuttgart 2007.

[7] IPCC, The IPCC 4th Assessment Report. Climate Change 2007, Adapation and Vulnerability, Geneva 2007, www.ipcc.ch.

[8] Johanning, L., Funke, C., Bossert, T., Rendite oder Risiko? Risikokontrolle im Asset Management. Risikomanager, 06/2006, pp.14-18.

[9] Kuruc, A., Financial geometry - a geometric approach to hedging and risk management. Harlow 2003.

[10] Oehler, A., Unser, M., Finanzwirtschaftliches Risikomanagement, Bamberg 2002.

[11] Onischka, M., Orbach, T., Klima und Finanzmarkt. So investiert die Welt. Globale Trends in der Vermögensanlage, ed. Bierbaum, D., Wiesbaden 2008. pp. 77-97.

[12] Onischka, M., Climate Change will alter financial markets, Nikkei Ecology, No. 8./2007. p.129. [japan.]

[13] Pigou, A., The Economics of Welfare, Fourth Edition, London 1932.

[14] Reichling, P., Bietke, D., Henne, A., Praxishandbuch Risikomanagement und Rating, Wiesbaden 2007.

[15] Ronning, G., Mikroökonometrie, Berlin/Heidelberg 1991.

[16] Shim, J., Siegel, J., Handbook of Financial Analysis, Forecasting and Modelling, New Jersey 2001.

[17] Schwartz, P., Randall, D., An abrupt climate change scenario and its implications for United States national security, Washington 2003. www.icomm.ca/survival/pentagon climate change.pdf.

[18] Spreman, K., Valuation. München 2004.

[19] Stern, N., The Economics of Climate Change. The Stern Review. Cambridge 2007.

[20] WestLB Panmure, From Economics to carbonomics, London 2003. 